\title{
Fine Needle Aspiration Cytology Study of Male Breast Lesions: A Six Year Study
}

\section{Babai Halder ${ }^{\star}$ and Nirvana Rasaily Halder}

Department of Pathology, Mamata Medical College, Khammam, Telangana, India

*Corresponding author: Halder B, Department of Pathology, Mamata Medical College, Khammam, Telangana, India, Tel: +91-9573632267; E-mail: at.babai@gmail.com

Received date: July 27, 2018; Accepted date: August 08, 2018; Published date: August 14, 2018

Copyright: (C) 2018 Halder B, et al. This is an open-access article distributed under the terms of the Creative Commons Attribution License, which permits unrestricted use, distribution, and reproduction in any medium, provided the original author and source are credited.

\begin{abstract}
Background: Male breast lesions are comparatively less common. Gynaecomastia is the most common clinical and pathological abnormality of the male breast. Carcinoma of the male breast is much rarer than its equivalent female tumour. Fine needle aspiration cytology (FNAC) is widely used method in the management of breast lesions in women. However, FNAC is used much less often in male, mainly because male breast masses are less frequent. But it is one of the most reliable tools for diagnosis of male breast lesions.
\end{abstract}

Aims and objectives: To describe cytomorphological pattern and to determine the efficacy of FNAC in the diagnosis of male breast lesions.

MAC.

Materials and methods: A six year retrospective cross sectional study of male breast lesions was conducted by

Results and observations: A total of 111 cases of male breast lesions were subjected to FNAC. Among these, 107 cases $(96.40 \%)$ had benign diagnosis. Only 1 case $(0.9 \%)$ had malignant diagnosis. In 3 cases $(2.7 \%)$, smears were inconclusive. Among benign cases, gynaecomastia (90 cases, $81.08 \%$ ) was the most common lesion, followed by fibroadenoma ( 8 cases, $7.21 \%$ ), acute suppurative lesion ( 4 cases, $3.6 \%$ ) and others ( 5 cases, $4.5 \%$ ). Age of the patient ranged from 7 years to 85 years with mean age of 42.39 years. Most of patients had unilateral lesion (102 cases, $91.89 \%)$.

Conclusion: Gynaecomastia is the most prevalent male breast disorder. FNAC of male breast lesions is very accurate tool. Therefore, it should be used as initial diagnostic procedure of male breast lesions.

Keywords: Fine needle aspiration cytology (FNAC); Gynaecomastia; Fibroadenoma

\section{Introduction}

Lesions of male breast are not as common as lesions of female breast. Majority of lesions that come to surgical practice are gynaecomastia and carcinomas. Other lesions are extremely rare and include fibroepithelial tumors, Duct ectasia, papilloma and fibrocystic change [1]. Fine needle aspiration cytology (FNAC) is widely accepted as a reliable technique in the initial evaluation of palpable and nonpalpable breast lumps. The procedure is simple, safe, cost effective, minimally invasive and rapid. FNAC has high sensitivity, specificity and diagnostic accuracy [2-6]. FNAC is widely used method in the management of breast lesions in women. However, FNAC is used much less often in male, mainly because breast masses in males are less frequent. But it is one of the most reliable tools for diagnosis of the male breast lesions. Gynaecomastia is the most common cause of benign masses in the male breast. Carcinoma of the male breast is a rare disease representing $1 \%$ of all breast cancers and less than $1 \%$ of all cancer in men [7-17].

FNAC can be performed as an OPD procedure, is less traumatic to the patient than surgical biopsy, is cost effective and can provide rapid results on the same day [1]. Therfore it can be used as initial diagnostic procedure for male breast lesions.

The aim of this study was to describe the cytomorphological patterns of male breast lesions and also to determine the efficacy of FNAC in the diagnosis of male breast lesions.

\section{Materials and Methods}

A six year (May'2012 to April'2018) retrospective cross sectional study was done in Cytology section of Pathology department of Mamata Medical College, Khammam. FN Aspirates were performed in outpatient department from all male patients with breast lesions using 23 gauge needle and $5 \mathrm{ml}$ syringe. Air dried smears routinely stained with May-Grunwald-Giemsa stain and wet-fixed smears stained with Hematoxylin and Eosin stain and examined under microscope. Then smears were categorised into four major categories such as benign, malignant, suspicious of malignancy and inconclusive aspiration. Histopathologic diagnosis was obtained wherever available and the cytologic diagnosis was retrospectively correlated with histological findings. Finally statistical analysis was done by XLStat software and calculated the sensitivity, specificity and diagnostic accuracy of the aspirates. 
Page 2 of 4

\section{Results}

A total of 111 cases of male breast lesions were subjected to FNAC. Out of these, 107 cases $(96.40 \%)$ had benign diagnosis. Only 1 case (0.9\%) had malignant diagnosis. In 3 cases $(2.7 \%)$, smears were inconclusive and in these cases, biopsy was advised. Among benign cases, gynaecomastia (90 cases, $81.08 \%$ ) was the most common lesion, followed by fibroadenoma ( 8 cases, $7.21 \%$ ), acute suppurative lesion (4 cases, $3.6 \%$ ) and others (5 cases, $4.51 \%$ ) which included chronic mastitis, fibrocystic disease, usual ductal hyperplasia, mammary dysplasia and intraductal papilloma ( 1 each). 1 case $(0.9 \%)$ of malignancy (invasive ductal carcinoma) was encountered during the study period (Figure 1 and Table 1).

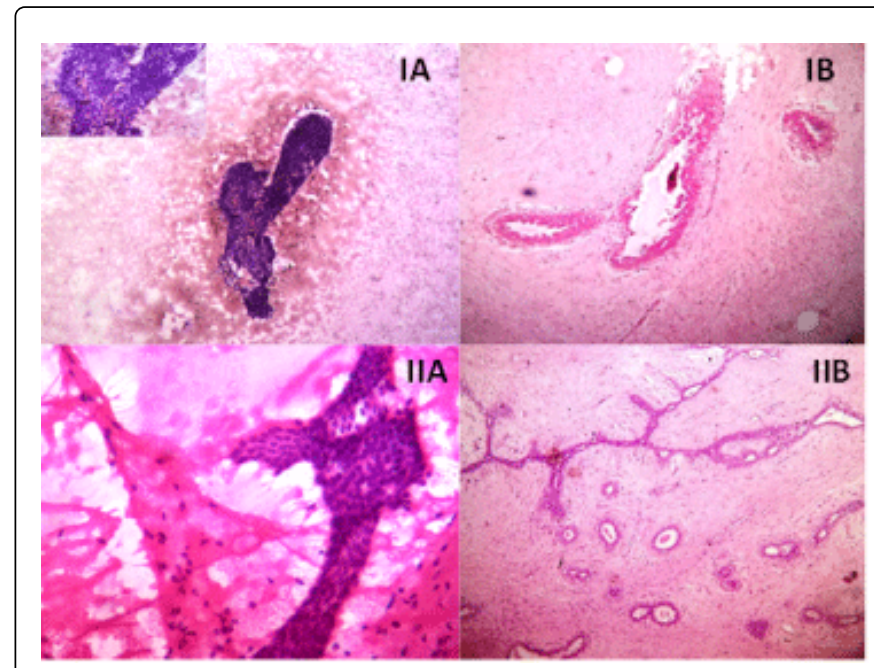

Figure 1: (IA) Cytological picture of gynaecomastia, showing cohesive aggregate of ductal epithelial cells and few naked nuclei (H\&E stain, 10x), inset picture in 40x; (IB) Histological picture of gynaecomastia, showing flat ductal hyperplasia with increased periductal vascularity (H\&E stain, 10x); (IIA) Cytological picture of fibroadenoma, showing cohesive sheet of ductal epithelial cells, stromal fragment and naked nuclei in the background (H\&E stain, 10x); (IIB) Histological picture of fibroadenoma, showing both intra and pericanalicular pattern of duct with proliferation of interlobular stroma (H\&E stain, 10x).
Age of the patient ranged from 7 years to 85 years with mean age of 42.39 years. Most of patients had unilateral lesions (102 cases, $91.89 \%)$, only few were bilateral lesions ( 9 cases, $8.11 \%$ ) (Figure 2).

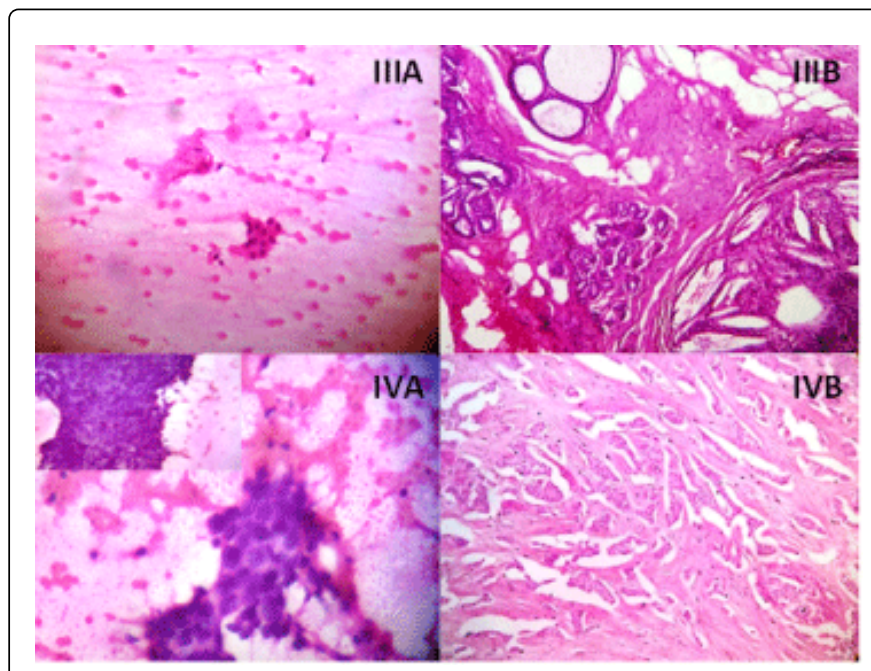

Figure 2: (IIIA) Cytological picture of fibrocystic disease, showing small cluster of metaplastic apocrine cells, cyst macrophage against eosinophilic proteinaceous background (H\&E stain, 10x); (IIIB) Histolological pictiure of fibrocystic disease, showing cysts, apocrine change and fibrosis (H\&E stain, 10x); (IVA) Cytological picture of invasive ductal carcinoma, not otherwise specified (IDC, NOS), showing malignant ductal cells in cluster with nuclear enlargement, pleomorphism and irregular chromatin (H\&E stain, $10 \mathrm{x}$ ), inset picture in 40x; (IVB) Histological picture of IDC, NOS, showing malignant ductal cells arrange predominantly in tubules with few nests, having moderate nuclear pleomorphism (H\&E stain, 10x).

Among benign cytologically diagnosed cases (107 cases), only 28 cases were histologically confirmed. 1 case of malignancy (invasive ductal carcinoma) was also histologically confirmed. Out of 3 cases in the inconclusive category that were advised biopsy, 1 case $(33.33 \%)$ proved malignant on histopathological examination while 2 cases (66.67\%) had a benign diagnosis (Table 2).

\begin{tabular}{|l|l|l|}
\hline SI. No. & Cytological finding & No. \\
\hline \multirow{2}{*}{1.} & Benign & $107(96.40 \%)$ \\
\hline \multirow{3}{*}{} & Gynaecomastia & $90(81.08 \%)$ \\
\cline { 2 - 3 } & Fibroadenoma & $8(7.21 \%)$ \\
\cline { 2 - 3 } & Acute suppurative lesion & $4(3.60 \%)$ \\
\cline { 2 - 3 } & Others & $5(4.51 \%)$ \\
\hline 3. & Malignant (Invasive ductal carcinoma) & $1(0.9 \%)$ \\
\hline \multirow{2}{*}{3.} & Inconclusive & $3(2.7 \%)$ \\
\hline
\end{tabular}

Table 1: Overall cytological finding of male breast lesions. 
Page 3 of 4

Out of 108 cases (excluding inconclusive cases), 1 case (100\%) was true positive and none of the cases was false positive. The number of true negative cases was $107(100 \%)$ and none of the cases were false negatives. Sensitivity and specificity of test was $100 \%$. Positive and negative predictive value was $100 \%$. Accuracy of the test was $100 \%$.

\begin{tabular}{|l|l|l|}
\hline \multirow{2}{*}{ Cytology } & Histology & \multicolumn{2}{|l|}{} \\
\cline { 2 - 3 } & Positive(malignant) & Negative(benign) \\
\hline Benign (28) & $0=$ False negative $(0 \%)$ & $28=$ True negative $(100 \%)$ \\
\hline Malignant (1) & $1=$ True positive (100\%) & $0=$ False positive $(0 \%)$ \\
\hline Inconclusive (3) & $1(33.33 \%)$ & $2(66.67 \%)$ \\
\hline Total (32) & $2(6.25 \%)$ & $30(93.75 \%)$ \\
\hline
\end{tabular}

Table 2: Cytologic and Histopathologic categories of 32 FNACs and statistical analysis.

Inconclusive smears were observed in $3(2.7 \%)$ of all cases. All of these cases were unsatisfactory due to scanty cellularity. Out of these, one case was diagnosed as malignant (invasive ductal carcinoma) and
2 cases were diagnosed as gynaecomastia on histopathological examination. Rate of inconclusive smears was more in malignant than benign lesions (Table 3).

\begin{tabular}{|l|l|l|}
\hline Histopathological diagnosis & Total no. of cases & No. of inconclusive smears \\
\hline Benign & 30 & $2(6.67 \%)$ \\
\hline Malignant & 2 & $1(50 \%)$ \\
\hline Total & 32 & $3(9.38 \%)$ \\
\hline
\end{tabular}

Table 3: Histopathologic categories of inconclusive smears.

\section{Discussion}

FNAC is one of the most reliable tools for diagnosis of the male breast lesions. It is cost effective, involves minimal discomfort to the patient and can be performed on outpatient basis.

In this study, Gynaecomastia was found as the most common male breast lesion (88.29\%). In a study done by Singh et al. [18], gynaecomastia $(84.3 \%)$ was most common male breast lesion.

In present study, mean age of the patients of gynaecomastia was 42.39 years and most patients presented in 2nd decade of life (21 cases). In a study by Gill et al. [19], mean age of gynaecomastia patients was 38.75 years and most patients presented in 3rd decade of life.

Most of cases of Gynaecomastia were unilateral (93.88\%) in present study. While a study done by Westenend et al. [20] showed $97.24 \%$ cases of gynaecomastia were unilateral.

Only 1 case $(0.9 \%)$ of male breast malignancy was noted in this study. While in a study conducted by Das et al. [21], prevalance of male breast malignancy were $3.77 \%$.

In this study, a statistical analysis of FNAC in male breast lesions and cytohistologic correlation was performed. Sensitivity, specificity, accuracy, positive and negative predictive value for diagnosis of malignancy was $100 \%$. Similar result was found in a study done by Kulwant Singh et al. [1]. In other studies, sensitivity ranges from $87 \%$ to $100 \%[11,13,21]$. Specificity is also reported very high, ranging from $78 \%$ to $100 \%[11,13,21]$. Positive predictive value, in studies done, ranges from $89 \%$ to $100 \%[11,20,21]$.
Inconclusive smears constituted $2.7 \%$ of all FNAC smears. In other literatures, inconclusive smears represented $8-22 \%$ of all smears $[11,13,21]$. Inconclusive smears in our study showed very poor cellularity, which preventing to give definite opinion about the smear.

FNAC is a blind procedure. Therefore, always we do not able to sample properly. Another reason is intrinsic nature of the lesion. Lesions with abundant fibro connective tissue sometimes do not provide enough epithelial cells for interpretation in case of FNAC breast (especially seen in cases of gynaecomastia). Malignancies with desmoplasia also yield poor cellularity.

Cytohistological correlation in our study was $100 \%$ in both benign and malignant cases. However, only 28 benign cases were histologically correlated.

\section{Conclusion}

From the present study, we concluded that gynaecomastia is the most prevalent male breast disorder. Malignancy in male breast is rare. FNAC of male breast lesions is very accurate tool which shows excellent specificity, sensitivity and cytohistological correlation. Therefore, it should be used as initial diagnostic procedure of male breast lesions.

\section{References}

1. Singh K, Pinto GWR (2015) A statistical analysis and cytohistologic correlation of fine needle aspiration cytology in lesions of male breast. IJPO 2: 215-218. 
Citation: Halder B, Halder NR (2018) Fine Needle Aspiration Cytology Study of Male Breast Lesions: A Six Year Study. J Cytol Histol 9: 515. doi:

Page 4 of 4

2. Nguansangiam S, Jesdapatarakul S, Tangjitgamol S (2009) Accuracy of fine needle aspiration cytology from breast masses in Thailand. Asian Pac J Cancer Prev 10: 623-626.

3. Kalhan S, Dubey S, Sharma S, Dudani S, Preeti, et al. (2010) Significance of nuclear morphometry in cytological aspirates of breast masses. J Cytol 27: 16-21.

4. Chaiwun B, Settakorn J, Ya-In C, Wisedmongkol W, Rangdaeng S, et al (2002) Effectiveness of fine-needle aspiration cytology of breast: analysis of 2,375 cases from northern Thailand. Diagn Cytopathol 26: 201-205.

5. Mendoza P, Lacambra M, Tan PH, Tse GM (2011) Fine needle aspiration cytology of the Breast: The nonmalignant categories. Pathology Research International 12: 80-85.

6. Rocha PD, Nadkarni NS, Menzes S (1997) Fine needle aspiration biopsy of breast lesions and histopathological correlation. Acta Cytol 41: 705-712.

7. Pailoor K, Fernandes H, Jayaprakash CS, Marla NJ, Murali KS (2014) Fine needle aspiration cytology of male breast lesions-a retrospective study over a six year period. JCDR 8: FC13-FC15.

8. Rosen DG, Laucirica R, Verstovsek G (2009) Fine needle aspiration of male breast lesions. Acta Cytol 53: 369-374.

9. MacIntosh RF, Merrimen JL, Barnes PJ (2008) Application of the probabilistic approach to reporting breast fine needle aspiration in males. Acta Cytol 52: 530-534.

10. Wauters CAP, Kooistra BW, Heijden IMK, Strobbe LJA (2010) Is cytology useful in the diagnostic workup of male breast lesions? A retrospective study over a 16-year period and review of the recent literature. Acta Cytol 54: 259-264.

11. Lilleng R, Paksoy N, Vural G, Langmark F, Hagmar B (1995) Assesment of fine needle aspiration cytology and histopathology for diagnosing male breast masses. Acta Cytol 39: 877-881.
12. Feichter GE, Haberthur F, Gobat S, Dalquen P (1997) Breast cytologystatistical analysis and cytohistologic correlations. Acta Cytol 41: 327-332.

13. Joshi A, Kapila K, Verma K (1999) Fine needle aspiration cytology of male breast masses - nineteen years' experience. Acta Cytol 43: 334-338.

14. Bhat N, Rosato EF, Gupta PK (1990) Gynecomastia in a Mortician. Acta Cytol 34: 31-34.

15. Amrikachi M, Green LK, Rone R, Ramzy I (2001) Gynecomastia Cytologic features and diagnostic pitfalls in fine needle aspirates. Acta Cytol 45: 948-952.

16. Rai B, Ghoshal S, Sharma SC (2005) Breast cancer in males: A PGIMER experience. J Can Res Ther 1:31-33.

17. Coghill S, Howat A (2004) Inflammatory conditions and benign breast lesions. In: Gray W, McKee GT (2ndedn), Diagnostic Cytopathology. Elsevier, pp: 257-278.

18. Singh R, Anshu Sharma SM (2012) Spectrum of male breast lesions diagnosed by fine needle aspiration cytology: a 5-year experience at a tertiary care rural hospital in central India. Diagn Cytopathol 40: 113-117.

19. Gill MS, Kayani N, Khan MN (2000) Breast diseases in a males - a morphological review of 150 cases. J Pak Med Assoc 50: 177-179.

20. Westenend PJ, Jobes C (2002) Evaluation of fine needle aspiration cytology of breast masses in males. Cancer 96: 101-104.

21. Das DK, Junaid TA, Mathews SB (1995) Fine needle aspiration cytology diagnosis of male breast lesions. A study of 185 cases. Acta Cytol 39: 870-876. 